\title{
Analysis of Communication Barriers to Distance Education: A Review Study
}

\author{
Fahme DABAJ, Ayşegül YETKİN \\ Eastern Mediterranean University
}

\begin{abstract}
Now that the technology is changing fast and due to the multitude of people demands and conditions, traditional educational systems and institutions have to provide additional educational alternatives. There are some educational establishments contributing to these conditions and demands by developing and offering distance education programs. In such programs, teachers and the students do not establish a face to face communication thus creating difficulties and are separated by physical distance and time. As a result alternate media sources are used to deal with these difficulties.
\end{abstract}

That is to say, different delivery systems such as computer mediated communication systems, video tapes, printed material, cassettes and instructional television are used to deliver instructions from tutor to students. Moreover, the universities have the advantage of using World Wide Web to deliver the instruction to nearly any node in the world, regardless of the physical distance and time because of the developments in the Internet and the global network systems,

Almost all institutions which are offering distance education should try and find the most effective program and make sure that it is a sufficient replacement for face-to-face education. Its effectiveness of course is dependent on how interactive the process is and how it overcomes the communication barriers among the members involved.

Communication barriers, on the other hand, as in any communication process, also exist in distance education because of such reasons as the physical distance between members, the difficulties of dealing with new media, having time constraints and restrictions, background knowledge of distance education, incompetence in skills of using technology, and the interactivity level of the process. Put all together, effective distance education process 


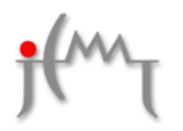

Online Journal of Communication and Media Technologies

Volume: 1 - Issue: 1 - January - 2011

becomes almost impossible. The levels of these barriers are different in different institutions or in different programs and in different delivery systems used.

\section{Introduction}

The meaning of the communication in education and distance-learning are best understood, when the types of communication among the participants involved in distance education and some related communication theories are mastered thoroughly. The communication among the students and the communication between the members and the content should not be underestimated even though the communication between the teacher and the student is a vital element of successful distance education. If it is important to attain success in teaching and learning, barriers between the sender and the receiver of the message should be eliminated. Consequently, all strategies of learning and teaching during the delivery of instruction should not reflect any barrier (Nasseh, 1997).

Different types of communication are employed in the network educational environment, such as:

- Work in collaboration with a teacher;

- Work in collaboration with other students;

- Work in collaboration with online course through a mass media.

Telecommunication technologies offer a new scope to the mentioned communication types. They make it possible to travel beyond the physical distance and time. Nevertheless, it is essential to investigate communication via telecommunication technologies in detail besides the communication theories related with education, mass media, group interaction, knowledge and skill differences of users, and the preferences and the use ability of the involved members.

Human beings need to create effective communication and establish contacts in order to survive. In other words, they need communication to provide connections and create effective understanding, get information and express feelings. Therefore, the effectiveness of the communication is measured by the message sent and feedback received. Furthermore, people's personal, social and economic needs are also affecting communication. 


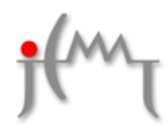

Online Journal of Communication and Media Technologies

Volume: 1 - Issue: 1 - January - 2011

Communication is a learnt activity and is provided by the media which forms a bridge between the sender and the receiver (Dimbleby, et al., 1992).

The quality in communication and its effects on people's lives can be improved once we clarify its meaning and also the meaning of education which is the major concept on which a structured society is based. Communication is a process that includes linear, interactive and transactional views from different perspectives barriers (İşman et al., 2003). One-way communication where the sender cannot get any feedback is the linear view. On the other hand, the interactive view is the existence of a two-way communication which includes feedback as well as nonverbal communication, but it does not include simultaneous sending- receiving feedback that transactional view underlines. Therefore, when creating mutual understanding in communication physical, psychological and semantic barriers are all eliminated. (İşman et al., 2003).

As said before, communication is an important element of life. In order to increase productivity at work, organizations and schools should have effective communication. This is more important when it comes to education which is a tool for the welfare of the society. People socialize via communication and thus perform desired behaviors. Because of these reasons, preventing the barriers in communicating will provide a clearer field of experience between the sender and the receiver. People should find shared points by analyzing our encoding, decoding stages and channel by eliminating our unfairness about the backgrounds in order to create meaningful understanding. There is no perfect communication; this is almost inevitable and creating a qualified communication process is essential to create a permanent understanding especially in the teaching-learning process and establishing reasonable communication to improve meaningful learning of the students.

Today, e-learning or distance education are the result of technology. As a result, traditional teaching styles are transformed to technology-based teaching. Distance education is a new trend in education which makes it possible for everyone to learn better and provide options under the constructivist approach. Technological devices like audio cassette, telephone, compact disc, etc become a major necessity for distance education. Students have a more flexible education opportunity because of distance education. But, on the other hand, lack of 


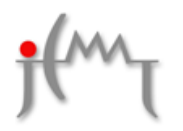

face-to-face contact with teachers may result in a loss of motivation. Besides, there are many barriers in teaching and learning process of distance education (Galusha, 2001).

Most common barriers are the unawareness of the roles as teachers and students. Studies show that the barriers of distance education fall into such categories as cost, motivators, feedback and teacher contact, student support and services, alienation, lack of experience and training. Moreover, due to the lack of information about their roles in distance education there is faculty and organizational barriers. In addition, course content on the other hand constitutes another barrier and should be modified in distance education (Galusha, 2001). Therefore, to create effective and qualified distance education all barriers must be realized and eliminated.

There are some differences between the types of communication in distance learning and classroom-based learning. Firstly, due to resistance to change and anxiety while engaged in distance education, students and teachers can have psychological problems. Technical barriers during communicating, on the other hand, can be experienced by students and teachers due to a lack of experience about technology and they may have semantic barriers in their communication by misunderstanding announcements (Perreault, et al., 2002). Therefore, it is important to eliminate communication barriers if qualified and effective distance education is aimed at.

\section{Communication Theories}

The present study is ultimately related to three theories of communication namely, Diffusion of Innovation, Knowledge Gap and Uses and Gratification.

Diffusion of Innovation: this theory explains the behavior of people toward a new idea in technology, the process of adaptation to it and the way in which innovation is communicated through certain channels over time among the members. The theory also explains how people with strong opinions influence the masses through the media. New ideas and innovations frighten people and cause frustration. This is due to the fear that new ideas may fail. Similarly in the case of people who are changing their teaching-learning process from the traditional faceto-face to a technologically mediated education encounter these difficulties. 


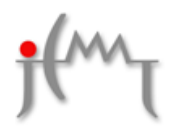

Online Journal of Communication and Media Technologies

Volume: 1 - Issue: 1 - January - 2011

The adoption process, with respect to the amount of time, to the new idea or innovation differs from person to another. Ryan and Gross (cited in: Everett M. Rogers and Karyn L. Scott, 1997) divide the adopters into five categories:

1.Innovators: ability to understand and apply complex technical knowledge;

2.Early adopters: greatest degree of opinion leadership in most systems;

3.Early majority: interact frequently with peers;

4.Late majority: cautious and skeptical;

5.Laggards: suspicious of innovations.

Knowledge Gap Theory: the theory, originally hypothesized by Tichenor, Donohue and Olien "studies that "as the mass media information in a society increases, those with higher socioeconomic status acquire this information faster than low socioeconomic status ones" (1970; cited in Eric J. Jenner, 2001). Other researchers (McLeod and Perse, 1994; cited in Eric J. Jenner, 2001) find that communication skills, prior knowledge, social contacts, education and exposure are the principal reasons for the discrepancy of information.

So with the influence of this theory, the students' socioeconomic status, background knowledge and their communication skills should be analyzed in order to find out whether the mentioned above are causing any barrier to distance education.

Uses and Gratification: is a theory which explains the ability of a media use in satisfying different needs of people. Blumer and Katz (1974; http://www.uky.edu/ drlane /capstone/mass/uses.htm) suggest that media users take an active role in the communication process by choosing and using the media. They use the media which has the most influence on them. So, different media have different influence on people that use them with different degrees. In distance education nowadays, the most popular media in conveying the instruction is the Internet via computers. Since the students do not choose these media themselves these technological devices influence students in different ways. These diverse influence levels are other barriers in communication to distance education.

So methods to eliminate these communication barriers, by increasing the ability of Internet access, student to student interactions, student to instructor interactions, student to content interactions and student/instructor motivations which makes the distance education program more effective, interactive, and even more attractive should be explored. 


\section{Problem Statement}

Most Universities offers online courses and an online degree program through asynchronous Internet-enabled instruction which is based mainly on course materials on a website. Asynchronous instruction is more widely used than the synchronous ones. Synchronous computer mediated communication used in distance education such as the online video conferencing is very expensive and need more advanced and well developed infrastructure to transfer huge amounts of data, audio, and video streams immediately to the students at a distance.

\section{Significance of the Work}

Once communication barriers to distance education are clarified, a major step in overcoming all difficulties is achieved. It is then necessary to get effective and meaningful communication for revising the structure and effectiveness of distance education. Distance education is a new application at some universities; therefore, it is expected to have some kinds of barriers especially in communication. For this reason, the great problem statement of this research study is to define the communication barriers in distance education. Negative dimensions are created by communication barriers which hinder the effectiveness of the education process and the productivity of all facilities and opportunities are therefore, decreased.

If the web site is developed and designed in a way to maximize the course requirements, webbased instruction in distance education then can be efficient enough to satisfy student needs, and make the communication process more interactive. To overcome the communication barriers raised by an asynchronous text-based method of instruction such as students' frustrations, isolation and belonging feelings, and the fear of using the technology such factors are very important (Hara, 1998).

The amount of contact the student has with the instructor determines the interactivity in an online program, with his peers, and with the course material (Sherry, 1996). This enables the students and instructors change their roles from the traditional instructor-centered to learner- 


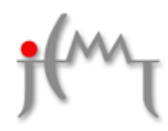

centered process, and encourage the students to seek for their answers and build their own knowledge from their own experiences. The more interactive the process is and the more students' role in it, the fewer barriers will be faced in an online distance education environment.

\section{Review of Related Literature}

The following literature review shows work done by researchers. All are related with communication barriers to distance education and the important communication theories which explain the diffusion of innovation with telecommunications, the knowledge gap between the members involved in distance education and the uses and gratification of the users of the mass media.

According to Galusha (1997) distance education gives people (students) greatest possible control over the time, place and pace in education; however, it has problems due to loss of student motivations since there is no face-to-face contact, startup cost and lack of faculty support. Such problems are categorized into three main groups as student barriers, faculty barriers, and organizational barriers. Problems and barriers encountered by students are costs and motivators, the feedback and teacher contact, the student support and services, the alienation and isolation, the lack of experience, and training related. Barriers related with faculty are the result of the lack of staff training, the lack of support for distance learning, and the inadequate faculty selection for distance training. Barriers encountered by the organization are the infrastructure and technology related problems, and the present challenge.

Heidi et al. (2002) examine the ideal combination of self-paced learning and interactivity is offered by distance education. Such learning requires online discussions, email support collaboration and interactive presentation of the students. All of which are possible through a healthy communication between participants and design groups for overcoming barriers to a successful delivery of distance learning courses.

Asirvatham (2000) points out that opportunity to educate work force for all companies and industries could not be always possible in a classroom-oriented learning atmosphere for all to participate. Therefore, distance education becomes a powerful advantage to overcome great distance problems among the education institutions and people. Alternative ways of technology provide sufficient tools to establish a healthy communication and interaction 


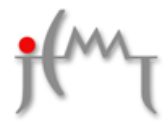

Online Journal of Communication and Media Technologies

Volume: 1 - Issue: 1 - January - 2011

among members in distance education. And regardless of all its problems, distance education is a good opportunity to compete with traditional classroom format.

Eisinger (2000) points out that that education showed an evolution from chalk and blackboard education to distance online learning activities. The study defines adult educators and the importance of understanding learner's autonomy as being instructors. In addition to this, there are some aspects like the lack of non-verbal cues which creates misunderstanding through the global interaction. Also, challenges to distance education are created due to the different needs and expectations of every learning environment.

According to Berge (1998), impediments to online teaching and learning can be situational, epistemological, philosophical, psychological, pedagogical, technical, social, and cultural and include faceless teaching, fear of computers replacing faculty, diffusion of value traditionally placed on getting a degree, faculty culture, lack of an adequate time-frame to implement online courses. It is easy to go wrong when learning system is technologically advanced, there is resistant to change, and the lack of technological assistance is present. The most critical barriers, as Berge found in his survey, appear related to person's resistance to or fear of the many changes that must occur at the individual and organizational level, the lack of support for the changing roles of students and teachers, and other barriers arising from difficulties in assessment.

Berge (2001) also points out that toward the use of distance education organizations or administrations face different barriers. The study tries to find out if there is any unknown barrier to distance education which is different from technical and interaction problems. The emphasis of the research study is on designers or organizations of distance education and their reflective action to distance education.

Muilenburg and Berge (2001) point out the underlying constructs that comprise barriers to distance education in their exploratory factor analysis research. The ten factors found are administrative structure, organizational change, technical expertise, social interaction and quality, faculty compensation and time, threat of technology, legal issues, evaluation/effectiveness, access, and student support services. To determine these ten factors, 


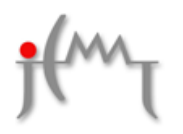

Online Journal of Communication and Media Technologies

Volume: 1 - Issue: 1 - January - 2011

they made a survey with sixty four different barrier items to 2054 members, and concluded that some barriers overlap with one or more different factors.

Truman (1995) concludes that the methods and techniques to accomplish learning will be the most important. Those that eliminate communication barriers confront by nontraditional learners or students. In her study, that the delivery system in distance education may not be so important, she discussed the important barriers like money, equipment, time, student information perceptions and their understanding how the technology itself shapes the information it carries to differentiate junk information from facts.

Pajo (2001) finds that the different roles of personal and attitude wise barriers predict current use and future intentions to adopt web-based technology. Current use of the technology is closely associated with personal barriers of those who lack competence in skills needed to use web-based delivery in their distance education. These personal barriers may hinder the individual from transferring his/her intentions into behavior.

Leach and Walker (2000) argue that the instructor's feedback to students is vital in distance education for their self-evaluation, task orientation, instructor support, and flexibility. Also they point out that the amount of student's experience with technology is directly correlated in determining if technology used in distance education is a barrier. All technology concerns must be minimized, and the programs offered must be designed accordingly if a successful online education is to be attained.

Cucek (2001) in his research study on distance education students he asks questions to Boise State University students in order to measure students' satisfaction with their distance education classes, perceived access to support services, and differences in their "classroom" behaviors in distance education and traditional face-to-face classes. The answers are mainly concentrated upon main problems (barriers) to the successful completion of their distance education courses. Almost all responses are related to course issues, time issues, personal issues, administrative, and technical issues. Course related barriers are the lack of interaction, course structure and accessing resources. Barriers related with time were the lack of time, personal commitments, and course work that takes too much time. Motivation and self- discipline comprised personal issues. The lack of expertise made up the technical problems. 


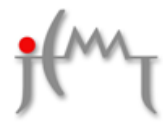

Finally, administrative problems are related to cost, course availability, obtaining course materials, and administrative support.

\section{Conclusion}

It can be concluded from the literature review that there are barriers to establishing and maintaining distance education programs, and communication barriers to using them. None the less, the investigation is still in progress, and the possible solutions to the problems outlined by the researchers, are still analyzed. The barriers to distance education have been identified as diverse problems, facing the members involved, in multiple dimensions.

In general, the barriers to distance education can be divided into three main categories;

- Barriers from students' point of view

- Barriers from instructors' point of view

- Barriers from administrative point of view

But if barriers to distance education are combined from all perspectives, they can be categorized into six (Zane L. Berge);

- Technical

- Infrastructure/Support Services

- Social

- Prerequisite Skills

- Motivation

- Time/Interruptions

Technical: The online system and the software currently used in e-learning must be user friendly.

Infrastructure/Support Services are issues in the instructor or organization control according to students.

Social: A friendly and social learning environment in learning is promoted should be created online. This means improving human relationships, developing group cohesiveness, 


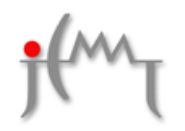

maintaining the group as a unit. In other words, it is important to help participants to work together for a mutual cause.

Students believe that before entering the online classroom, prerequisite skills must be mastered to a certain degree.

Motivation has to do with the psychological processes that cause students to persist in meeting their learning goals.

Time/Interruptions are a factor affecting perceived barriers to ones time in learning online and the interruptions that may disrupt ones learning.

All barriers regardless of the categories seriously overlap and merge together. It may then be concluded that there is a common and important barrier to distance education and this is the degree of communication between the members of distance learning/teaching process.

Because there is a direct communication between the instructor and the students, it is believed that the traditional face-to-face education is better than distance education. Even so, traditional face-to-face learning/teaching process continues to have many communication problems which need to be examined and solved as well.

It may be concluded that there are factors affecting communication in distance education. If the area of investigation is to concentrate on the student perspective and focus on having distance education via internet, the factors then can be divided into two major categories; unhidden and hidden barriers.

\section{Unhidden barriers:}

Writing skills problems: In a distance education program the used interaction medium is heavily text based, and this therefore, makes students' interactions less, therefore, lowering the students' written communication skills degree.

Lack of expertise with technology and the new medium: Since not all students are familiar with the used technology in distance education, they face problems and need more time to overcome the barriers of adaptation and the lack of experience with the new technology. 


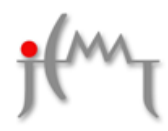

Online Journal of Communication and Media Technologies

Volume: 1 - Issue: 1 - January - 2011

Cost of communication: Distance education requires tools and devices to be used in communication such as computers and the related devices, so some students may face problems in purchasing them due to their low budget.

Language deficiencies: In a distance education program students' interactions become less, if they are interacting in a different language than that of the students' mother tongue

Web site access: Another barrier preventing or reducing the effective communication between the members in the distance education program is problems related with the infrastructure between the sender and receiver and the bandwidth limitations of the transmission.

\section{Hidden barriers:}

Resistance to new technology: Students with insufficient experience with technology and computers in their prior education and their daily lives, show more resistance to using the technology and computers. However, students who were familiar with the technology, thus, accepting the new updates easily.

Fear from technology: Persons with little or no experience with new devices in their daily lives felt that the new technology, especially computers, was complex devices to operate and they might damage or harm them with improper use. Such feeling reduces the interaction and communication between students and other involved members.

Belief in traditional education: The traditional classroom based education is changing towards online distance education, yet there are students who still believe in the traditional medium, and they do not accept the new trend. This as a result, lowers their motivation in the education process. This lack of motivation then decreases the communication between members.

Feeling of isolation: Students feel that they are isolated from each other in an asynchronous type of distance education especially in text-based online programs where the interactivity is at a minimum, and this feeling results in negative attitudes toward the course and reduces the communication between them.

Bad design and shape of the conveying medium: In internet-enabled distance education programs, the web design is a very important factor in education. If a web design is bad for a course then the students will have bad impression toward the course, which will result in a decrease in the interactivity between the students and the course or program. 


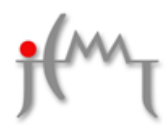

Online Journal of Communication and Media Technologies

Volume: 1 - Issue: 1 - January - 2011

No face-to-face communication: It is still believe by some that a better communication is achieved when the sender and receiver interact face to face. Therefore, bearing this in mind they refuse or resist communicating via technology.

Lack of direct feedback: In internet-enabled online programs communication process is prevented, because the transmission of information is one sided, so the students' communication with their instructors is minimized.

No pressure to respond: For any asynchronous type of communication, as text-based online courses program, there is no pressure to respond, this makes students with little or no preparation to course requirements, or who have other problems, escape from the quick respond to the course instructor or to the other students in program.

Therefore, research should assess educational concerns in using the Internet for distance education and will seek answers to the following questions:

- What are the communication barriers to effective Internet use in online courses?

- Is there a relationship between students' background characteristics and the barriers they confront in distance education?

- What are the strategies for reducing communication barriers to Internet use in online course activities?

\section{References}

Asirvatham, Sandy. (2000). Beyond the distance barrier. Journal of Property Management v. 65 no5, p. 42-8. http://www.fmlink.com/ProfResources/Magazines/ article.cgi?Journal of Property Management:jpm1100a.htm

Berge, Zane L. (1998). Barriers to Online Teaching in Post-Secondary Institutions: Can Policy Changes Fix It?. Online Journal of Distance Learning Administration. 1(2). http://www.westga.edu/ distance/Berge12.html

Berge, Zane L. et al. (2001). Obstacles faced at various stages of capability regarding distance education in institutions of higher education. TechTrends v.45 no4, p. 40-5. http://www.emoderators.com/barriers/hghred_stgs.shtml

Cucek, Mira (2001). Student Perceptions of their Distance Education Courses. Research Report 2001-04. http://www2.boisestate.edu/iassess/Reports/RR 2001-04.pdf Dimbleby, Richard et al. (1992) "More than words: An Introduction to Communication". Rutledge, New York. http://www.amazon.com/exec/obidos/tg/detail/- 


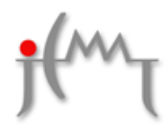

/0415170079/ref=lib_rd_next_8/103-5969443-

$4818210 ? \mathrm{v}=$ glance $\& \mathrm{~s}=$ books $\& \mathrm{vi}=$ reader $\& \mathrm{img}=8 \#$ reader-link

Eisinger, Jane. (2000). Education Evolution. Association Management v.52 no13, p. 52-9.

http://www.hermanek.cz/mark404/articles/acad6_distancedu.htm

Eric J. Jenner (2001). Public Affairs Engagement and the Digital Divide. Paper presented in Symposium on the Digital Divide. Manship School of Mass Communication, Louisiana State University. http://communication.utexas.edu/college/digital_divide_ symposium/papers/ jenner.doc

Everett M. Rogers and Karyn L. Scott (1997). The Diffusion of Innovations Model and Outreach from the National Network of Libraries of Medicine to Native American Communities. http://nnlm.gov/pnr/eval/rogers.html

Galusha, Jill M. (1997). Barriers to Learning in Distance Education. University of Southern Mississippi. http://www.tcom.ohiou.edu/ouln/Barriers to Learning in Distance Education.htm

İşman, A. et al. (2003). "Communication Barriers in Distance Education”, The Turkish Online Journal of Educational Technology, Volume 2, Issue 4.

Hara, Noriko (1998). Students' Perspectives in a Web-Based Distance Education Course. Indiana University. http://php.ucs.indiana.edu/ nhara/paper/ mwera98.htm

Leach, Karen and Walker Scott (2000). Internet-Based Distance Education: Barriers, Models, and New Research. http://itouch.net/ swalker/smec/internet_based_distance_ education.pdf

Mulilenburg, Lin and Berge Zane L. (2001). Barriers to Distance Education: A Factor Analytic Study. The American Journal of Distance Education. 15(2): 7-22. http://www.emoderates.com/zberge/fa_ajde_050401.shtml

Nasseh, Bizhan. (1997 ). "A Brief History of Distance Education”. http://www.seniornet.org/edu/art/history.html

Pajo, karl (2001). Barriers to the Uptake of Web-based Technology by University Teachers. Journal of Distance education. 16(1). http://cade.icaap.org/vol16.1/ pajoetal.html Perreault, Heidi et al. (2002). Overcoming Barriers to Successful Delivery of Distance Courses. Journal of Education for Business v. 77 no6, p. 313-1. http://proquest.umi.com/pqdweb?index $=0 \&$ did $=000000239597851 \&$ SrchMode $=1 \&$ sid $=$ 1\&Fmt=4\&VInst=PROD\&VType=PQD\&RQT $=309 \&$ VName=PQD\&TS=1061987666 $\&$ clientId $=48120 \#$ fulltext 
Sherry, L. (1996). Issues in Distance Learning. International Journal of Educational Telecommunications, 1 (4), 337-365. http://carbon.cudenver.edu/ /sherry/pubs/ issues.html

Truman, Barbara E. (1995). Distance Education in Post Secondary Institutions and Business. Paper presented for an Instructional Technology Graduate Class, University of Central Florida. http://pegasus.cc.ucf.edu/ btruman/dist-lr.html 